\title{
Anti-hyperglycemic activity of encapsulated Java tea-based drink on malondialdehyde formation
}

\author{
Joncer Naibaho $^{1}$, Mega Safithri², Christofora Hanny Wijaya ${ }^{{ }^{*}}$ \\ ${ }^{1}$ Department of Food Science and Technology, Bogor Agricultural University, Bogor, Indonesia. \\ ${ }^{2}$ Department of Biochemistry, Bogor Agricultural University, Bogor, Indonesia.
}

\section{ARTICLE INFO \\ Received on: 17/08/2018 \\ Accepted on: 06/03/2019 \\ Available online: 18/04/2019}

\section{Key words:}

Diabetes mellitus,

Java-tea based drink, micro-encapsulation, nano-encapsulation, lipid peroxidation.

\begin{abstract}
Nano-encapsulated Java tea-based beverage was previously reported capable of demonstrating the highest protective activity for Langerhans and beta-cell. The mechanism of anti-hyperglycemic activity, however, has remained unclear. This research aimed to study the mechanism of the beverage as an anti-hyperglycemic encapsulated functional drink through its role in malondialdehyde formation in streptozotocin-induced diabetic Sprague Dawley rats. The rats were divided into four groups: (A) normal rats as negative control, (B) untreated diabetic rats as positive control, (C) diabetic rats treated with micro-encapsulated drink $(3.64 \mathrm{ml} / 200 \mathrm{~g})$, and (D) diabetic rats treated with nano-encapsulated drink $(3.64 \mathrm{ml} / 200 \mathrm{~g})$. The intervention was conducted for 44 days. Malondialdehyde level was measured periodically every 2 weeks, body weight and blood glucose level were measured periodically every week for 6 weeks. Malondialdehyde level analysis in vitro was carried out as a comparison. Compared to malondialdehyde (MDA) level on positive control group, encapsulated Java tea-based beverages intervention attenuated the formation of malondialdehyde in diabetic rats from $36.63 \%$ to $51.95 \%$. In addition, micro- and nano-encapsulated drink suppressed the fluctuation of blood glucose level and body weight. In vitro assessment showed that micro- and nano-encapsulated drink suppressed the formation of MDA at $5.25 \%$ and $72.16 \%$, respectively. The anti-hyperglycemic activity of micro- and nanoencapsulated drink is shown by their ability to alleviate the MDA formation both in vivo and in vitro assessment.
\end{abstract}

\section{INTRODUCTION}

Diabetes mellitus is a chronic metabolic disease, which can cause complication (Vijay and Sharma, 2014). Oxidative stress may play a key role due to unbalance of prooxidant and antioxidant, leading to the formation of reactive and toxic species (Vijay and Sharma, 2014). It is related to the production of malondialdehyde and the inhibition of antioxidant activity (Fatani et al., 2016). Chronic hyperglycemia could damage the organs and cells because of the production of reactive species (Surya et al., 2014). The reactive species could be used as an indicator to study the mechanisms of degenerative diseases (Niki, 2013).

\footnotetext{
${ }^{*}$ Corresponding Author

Christofora Hanny Wijaya, Department of Food Science and Technology, Bogor Agricultural University, Bogor, Indonesia.

E-mail:hazemi@indo.net.id
}

Diabetes mellitus type II leads to increased oxidation of fatty acids because of the formation of free radicals and level of oxidative stress (Madiseh et al., 2016). Oxidative stress decreases the insulin sensitivity and damages beta-cells of the pancreas (Madiseh et al., 2016). Multiple oxidation of polyunsaturated fatty acids by lipid peroxidation generates 4-hydroxynonenal and malondialdehyde (MDA) (Gaschler and Stockwell, 2017). MDA is a highly reactive substance as an end product of the lipid peroxidation. Its reactivity is corresponding to cell damage and degenerative diseases (Gaschler and Stockwell, 2017). The increasing level of lipid peroxidation can be prevented by retarding peroxidase formation and peroxidase toxicity (Gaschler and Stockwell, 2017). In this regard, antioxidant could inhibit those deleterious activities (Madiseh et al., 2016).

Medical plants are well known for having antioxidative abilities due to their bioactive components such as phenolics and flavonoids (Krishnaiah et al., 2011). The use of synthetic medicines and antioxidants has been regarded less desirable due to their possible harmful side effects; thus, copious studies on 
antioxidant activity of medical plants have been made to substitute the synthetic one (Ezgi and Vural, 2017). Their antioxidant activity may vary, depending mainly on the type of bioactive compounds and abundance (Alok et al., 2014).

Java tea (Orthosiphon aristatus Bl Miq) is commonly known as "kumis kucing" in Indonesia. It has been used widely as a herbal medicine for its content high antioxidant activity (Noguchi et al., 2013). Java tea extract-based drink was enriched with various herbal plants possessing a high antioxidant activity, such as ginger, turmeric, citrus hystrix, citrus aurantifolia, and sappan woods extract (Wijaya et al., 2007). The formulated drink had a high antioxidant activity between 500 and 800 ppm AEAC. Furthermore, previous experiment using high performance liquid chromatography asserted that the bioactive compounds in this functional drink were found similar to those contained in raw material extracts (Indariani et al., 2014). The drink was also found able to increase the glucose absorption in ex vivo assay (Wijaya et al., 2010), suggesting that it shows antihyperglycemic properties. In addition, the formulated drink using simplicia extracts has been reported for its high antioxidant activity (Wijaya et al., 2018).

The antihyperglycemic effects of formulated Java teabased functional drinks were investigated on the diabetic mice. The drink was reported to inhibit the incremental of blood glucose level and delay pancreatic beta cell damages. However, the development of its ready-to-drink product remained as a critical challenge due to its less stability during storage, where the antioxidant levels decreased during the storage period (Indariani et al., 2014). To prevent this, encapsulation is a promising effort for its protective effect on the bioactive compounds (Ezhilarasi et al., 2012). The formulated Java tea-based beverage was encapsulated to increase the stability and its functional properties (Afandi, 2014).

Previous study found that encapsulation could improve consumer acceptance since it masks bitter taste of the product. However, the antioxidant activity of encapsulated drink was lower than that of ready-to-drink. This may display barrier effects of encapsulation, contributing to reduction of the released bioactive compounds, as previously reported in in vitro experiment (Wijaya et al., 2013).

On the other hand, encapsulated drink showed the best antihyperglycemic activity compared with ready-to-drink, based on in vivo assay. In that experiment, the encapsulation could also maintain body weight of the rats and suppress the blood glucose level during the experiment. Furthermore, histopathologic assay showed that encapsulated drink is beneficial for $\beta$-cells of pancreas (Rekasih, 2016).

The mechanism of the anti-hyperglycemic activity of the encapsulated drink has remained unclear. The purpose of this research is to study the mechanism of encapsulated drinks on the formation of malondialdehyde as an end product of lipid peroxidation over a longer period in experimental rats. The encapsulated drink was administrated to diabetic rats, as it has the higher anti-hyperglycemic activity than that on ready-to-drink form. Diabetic rats were administrated with micro-encapsulated and nano-encapsulated drink. The malondialdehyde formation is studied and compared with diabetic rats without treatment and non-diabetic rats group.

\section{MATERIALS AND METHODS}

\section{Materials}

Java tea(Orthosiphon aristaus B1Miq-WCSP), turmeric (Curcuma zanthorriza-WCSP), ginger (Zingiber officinaleWCSP), and sappan wood (Caesalpinia sappan L-ILDIS) were obtained from Biopharmaca garden, Bogor Agricultural University, while lime (Citrus aurantifolia-WCSP), lemon (Citrus limon-TRO), and kaffir lime (Citrus hystrix-WCSP) were purchased from a traditional market in Bogor. All plants were identified and deposited at Biopharmaca Research Center, Bogor Agricultural University, Indonesia. The voucher numbers are BMK0076042016, BMK0042072014, BMK0043052015, BMK0120092016, BMK0202092016, BMK0201092016, and BMK0189092016, respectively. All chemicals used were analytical grade. Linoleic acid, thiobarbituric acid, tetra-metoxi propane, acetic acid, ethanol pa, and $\alpha$-tocopherol were obtained from Sigma Ltd.

\section{Method}

Extraction

The extraction was carried out following the methods developed by Wijaya et al. (2007). The fresh Java tea (kumis kucing) leaves and sappan wood (kayu secang) were extracted by boiling them over 15 minutes in a closed pan containing as 30 $\mathrm{g}$ in $600 \mathrm{ml}$ water and $20 \mathrm{~g}$ in $500 \mathrm{ml}$ water, respectively. The extracts were filtered by vacuum filtration and concentrated with rotary evaporator until 1/3-part water remaining (150-200 ml). The extraction of ginger and turmeric was done without adding water. The tuber of ginger (jahe) and turmeric (temulawak) were crushed in an electric juicer followed by filtration. The filtrate was sedimented by kept in the refrigeration for 24 hours. The unsedimented part (30\%) was separated in to dark bottle. Finally, the extract of java tea, sappan wood, ginger, and turmeric was pasteurized and kept in the refrigeration before used. The extraction of lime, lemon, and kaffir lime was carried out through crushing in an electric juicer and filtration without adding water. Lime, lemon, and kaffir lime extracts were prepared immediately before micro- and nano-encapsulation process.

\section{Preparation of micro-encapsulated drink powder}

A $5.9 \mathrm{ml}$ extract of java tea was slowly mixed with 1.05 $\mathrm{ml}$ of sappan wood extract, followed by addition of ginger extract $(1.52 \mathrm{ml})$, turmeric extract $(0.2 \mathrm{ml})$, lime extract $(3.098 \mathrm{ml})$, lemon extract $(0.902 \mathrm{ml})$, and kaffir lime $(1 \mathrm{ml})$. Water was added until reaching a total volume of $100 \mathrm{ml}$. The solution was homogenized added with maltodextrin $(20 \mathrm{~g})$; the homogenized solution was dried using a mini spray drier. The dried powder was kept in refrigerator as micro-encapsulated stock (Rekasih, 2016).

\section{Preparation of nano-encapsulated drink powder}

Chitosan (2 g) was dissolved in $100 \mathrm{ml}$ of $2 \%$ acetic acid and stirred for 3 hours at 2,817.36 g. Nearly, $50 \mathrm{ml}$ of emulsifier (Tween80 $0.2 \%$ ) was added and stirred room temperature for 30 minutes. Afterward, a linking agent $(50 \mathrm{ml}$ of sodium tripolyphosphate) was added. Finally, the mixture was concentrated up to $10 \%$ of initial volume, stirred for 3 hours, and 
spray-dried. The dried powder was kept in refrigerator as nanoencapsulated stock (Wijaya et al., 2013).

\section{Particle size characterization and polydispersity index}

Sample (three drops) was dropped on an object and covered for analysis using dynamic light scattering. The measurement was done using nanoQ software version 2.2 (Makvern Instruments Ltd., UK) based on the refractive index and the viscosity of solvent according to intensity of laser beam. The laser beam was spotted on 30 different field points. The resulting data were analyzed by cumulant method (Wu et al., 2012).

\section{Animal study}

The experiment was carried out at the Animal Laboratory of The Tropical Biopharmaca Research Center, Bogor Agricultural University with an approved ethical clearance (No: 003-2018 KEH TROP BRC) and guidelines are described in The Animal Ethics Committee, Bogor Agricultural University. Sprague Dawley male rats $(250-300 \mathrm{~g})$ were obtained from the animal experimental facility of National Agency of Drugs and Food Control Badan Pengawas Obat dan Makanan (BPOM), Republic of Indonesia. They were fed with a standard diet and water ad libitum, under $50 \%-60 \%$ of humidity, with 12 -hour light. Streptozotocin $(10 \mathrm{mg} /$ $\mathrm{ml})$ was diluted in $50 \mathrm{mM}$ buffer sodium citrate $(\mathrm{pH}=4.5)$ and injected intraperitoneally in the fasted rats at $45 \mathrm{mg} / \mathrm{kg}$ dosage using syringe $1 \mathrm{ml}, 25-\mathrm{G}$. The rats were administered $10 \%$ sucrose solution for 24 hours and then they were fasted for 18 hours before checking their blood glucose level. The blood glucose level of diabetic rat was at $>150 \mathrm{mg} / \mathrm{dl}$ (Safithri et al., 2012; Ojiako et al., 2016).

\section{Animal experiment and treatment}

The rats were divided into four groups: (A) normal rats as negative control, (B) untreated diabetic rats as positive control, (C) diabetic rats treated with micro-encapsulated drink, and (D) diabetic rats treated with nano-encapsulated drink. Each group consisted of five rats. Micro-encapsulated and nano-encapsulated powder was diluted with plain water till total amount of 100 $\mathrm{ml}$ and administered at $3.64 \mathrm{ml} / 200 \mathrm{~g}$ body weight dosage. The experiment was carried out for 6 weeks. The fasting blood glucose level and the weight of rats were checked every week, while malondialdehyde levels in the blood serum were checked every 2 weeks. The blood for malondialdehyde assessment was collected intravenously. All of the rats were fed with a same amount of diet at $15 \mathrm{~g} /$ day.

\section{Measusurement of malondialdehyde level in rat's blood}

MDA level was measured using thiobarbituric acid (TBA) based on MDA-TBA serum formation via the nucleophilic mechanism. A standard curve was created using tetra-metoxi propane (TMP) by preparation of six different concentrations of TMP, namely $0,0.9,1.8,3.6,4.5$, and $6 \mu \mathrm{g} / \mathrm{ml}$. One milliliter of TBA (concentration $1 \%$ in acetic acid $50 \%$ ) was added to $4 \mathrm{ml}$ TMP and heated for 60 minutes at $95^{\circ} \mathrm{C}$ after which brought back to room temperature, followed by adding $5 \mathrm{ml} \mathrm{n}$-butanol:pyridine $(15: 1)$. The mixed solution was centrifuged for 15 minutes at
704.34 g. Finally, the absorbance was measured by a UV-Vis spectrophotometer at $532 \mathrm{~nm}$ of wavelength (Yagi, 1987).

A $1.2 \mathrm{ml}_{\text {of }} \mathrm{H}_{2} \mathrm{SO}_{4}$ was added to $0.3-\mathrm{ml}$ blood serum at the room temperature. After 10 minutes, $0.15 \mathrm{ml}$ of phosphotungstate acid $10 \%$ was added and centrifuged after 5 minutes at $704.34 \mathrm{~g}$ for 20 minutes. The sediment was separated from the solution. A $1.2 \mathrm{ml}$ of $\mathrm{H}_{2} \mathrm{SO}_{4}$ was added again into the solution and left for 10 minutes. Furthermore, a $0.15 \mathrm{ml}$ of phosphotungstate acid $10 \%$ was added, and after 5 minutes, it was centrifuged at $704.34 \mathrm{~g}$ for 20 minutes. The sediment was separated from the solution. A 0.5 $\mathrm{ml}$ of TBA $1 \%$ in $50 \%$ acetic acid was added to the solution, and then heated at $95^{\circ} \mathrm{C}$ for 60 minutes. The solution was cooled to the room temperature after which $2.5 \mathrm{ml}$ of n-butanol:pyridine $(15: 1)$ was added, continuously centrifuged at $704.34 \mathrm{~g}$ for 15 minutes. The absorbance was measured at $532 \mathrm{~nm}$ of wavelength with a UV-Vis spectrophotometer (Ohkawa et al., 1979).

\section{Fasting blood glucose level}

Fasting blood glucose levels were checked on the day before injection of streptozotocin (day 0). On days 2, 9, 16, 23, 30,37 , and 44 after injection, blood glucose levels were checked using electronic glucometer kit (Morakinyo et al., 2015). The data were recorded in $\mathrm{mg} / \mathrm{dl}$ of blood and represented in percentage of changes.

\section{Body weight changes}

During the experiment, the rat body weight was observed every week. The data were recorded in percentage of changes.

\section{Measurement of malondialdehyde in vitro}

MDA in vitro describes the inhibition of MDA formation by nano- and micro-encapsulated powder drink. The MDA inhibition activity is shown in comparison to vitamin $\mathrm{E}$ activity. The assessment was carried out by three steps: standard curve preparation of TMP, incubation period of linoleic acid, and finally, the inhibition of MDA formation activity from linoleic acid by powder drink. MDA in vitro was carried out followed the procedures by Kikuzaki and Nobuji (1993).

The standard curve of TMP was done by provided six level concentration of TMP, namely, $0,5,10,15,20$, and $25 \mu \mathrm{M}$. The TMP ( $1 \mathrm{ml}$ ) was reacted to $2 \mathrm{ml}$ of trichloro-acid (TCA) $20 \%$ and $2 \mathrm{ml}$ of TBA $1 \%$ in $50 \%$ acetic acid. The solution was heated $\left(100^{\circ} \mathrm{C}\right)$ for 10 minutes. The solution was cooled and centrifuged for 15 minutes $(704.34 \mathrm{~g})$. Finally, the absorbance was measured by a UV-Vis spectrophotometer at $532 \mathrm{~nm}$ of wavelength.

The incubation period of linoleic acid was determined by providing $6 \mathrm{ml}$ buffer phosphate $0.1 \mathrm{M}(\mathrm{pH} 7)$. Six milliliters of linoleic acid (100 mM in ethanol 99.8\%) was added into the buffer phosphate, followed by adding of $3 \mathrm{ml}$ demineralized aquadest. The solution was homogenized and incubated in a dark bottle in $40^{\circ} \mathrm{C}$ temperature. The solution was analyzed every 24 hours until the linoleic acid reached the highest absorbance. $2 \mathrm{ml}$ of TCA $20 \%$ and $2 \mathrm{ml}$ TBA ( $1 \%$ in acetic acid $50 \%$ ) were added in to 1 $\mathrm{ml}$ of incubated linoleic acid. The solution mixed was heated for 10 minutes $\left(100^{\circ} \mathrm{C}\right)$. The solution was cooled and centrifuged at $704.34 \mathrm{~g}$ for 15 minutes. The absorbance was measured by a UVVis spectrophotometer at $532 \mathrm{~nm}$ of wavelength. 
The last assessment was powder drink activity due to inhibit the formation of MDA from linoleic acid. Nano- and micro-encapsulated powder drink was provided into six different concentrations, namely, 0, 25, 50, 75, 100, and $200 \mathrm{ppm}$. A 200 ppm of alpha-tocopherol (Vitamin E) control positive also was provided as a comparison. Moreover, a blanco solution was provided by adding $2 \mathrm{ml}$ of buffer phosphate $0.1 \mathrm{M}(\mathrm{pH} 7)$ into 3 $\mathrm{ml}$ ethanol $99.8 \%$. One milliliter of sample solution was provided, following by adding $2 \mathrm{ml}$ of TCA $20 \%$ and $2 \mathrm{ml}$ of TBA (1\% in acetic acid $50 \%)$ and heated for 10 minutes $\left(100^{\circ} \mathrm{C}\right)$. The solution was cooled and centrifuged at $704.34 \mathrm{~g}$ for 15 minutes. The absorbance was measured by a UV-Vis spectrophotometer at 532 $\mathrm{nm}$ of wavelength.

\section{Statistical analysis}

Data were evaluated using analysis of variance in SPSS version 16 (SPSS Institute, Inc., Chicago, IL). Duncan test was used to determine significant difference at $p<0.05$.

\section{RESULTS AND DISCUSSION}

\section{Particle properties of encapsulated drink}

The nano-encapsulated drink powder had particle size of $217.7 \mathrm{~nm}$ and polydispersity index (PDI) at 0.796 (Fig. 1), while the value was $1,785 \mathrm{~nm}$ and 0.985 for micro-encapsulated drink powder. In term of nano-encapsulated drink powder, the value was in accordance with FDA (2012) regulations, i.e., 0-1,000 nm. PDI is defined as monodyspersion level and particle distribution, which ranges from 0 to 0.7 (Jardim et al., 2015). Particle size on previous research was $537.8 \mathrm{~nm}$ (Rekasih, 2016) and $224.3 \mathrm{~nm}$
(Wijaya et al., 2013). The difference in particle size is caused by the difference in deacetylation degree of the encapsulant used.

In our experiment, the diacylation degree of chitosan was $>85 \%$, which is different from previous studies, i.e., $>90 \%$ (Wijaya et al., 2013) and $>75 \%$ (Rekasih, 2016). Deacetylation degree affects the strength of sizing. Higher levels of deacetylation would result in smaller and uniform particles (Minagawa et al., 2007). In addition, a decreased particle size positively correlated to bioavailability of the bioactive compounds in metabolic system (Ozturk et al., 2014). The encapsulated drink is distributed faster to the cell and targeted organs for increasing of solubility (Arpagaus et al., 2017).

\section{Malondialdehyde level}

The MDA level was checked in the rat blood serum on days 2, 16, 30, and 44 after induction. MDA level of non-diabetic rats was stable at $<4.0 \mu \mathrm{M} / \mathrm{ml}$ during 6-weeks maintenance (Tabel 1). Yagi (1987) reported that MDA level for healthy and unhealthy was at \pm 3.42 and $>6.40 \mu \mathrm{M} / \mathrm{ml}$, respectively. The MDA level in diabetic positive rats $\mathrm{B}, \mathrm{C}$, and $\mathrm{D}$ (Table 1 ) was fluctuated during 44-day experiment. MDA was formed due to streptozotocin activity as free radical. MDA is formed when the amount of free radical is higher than that of antioxidant (Annadurai et al., 2014), which involved lipid peroxidation.

The formation of MDA in diabetic rats fed by microencapsulated drink (Group C) increased (Fig. 2) during first 16 days. The MDA level noticeably increased in initial stage, then slightly decreased after day 16 . The MDA level continued to decrease and reached healthy level on day 44. The dissimilar trend was observed in nano-encapsulated drink-treated diabetic
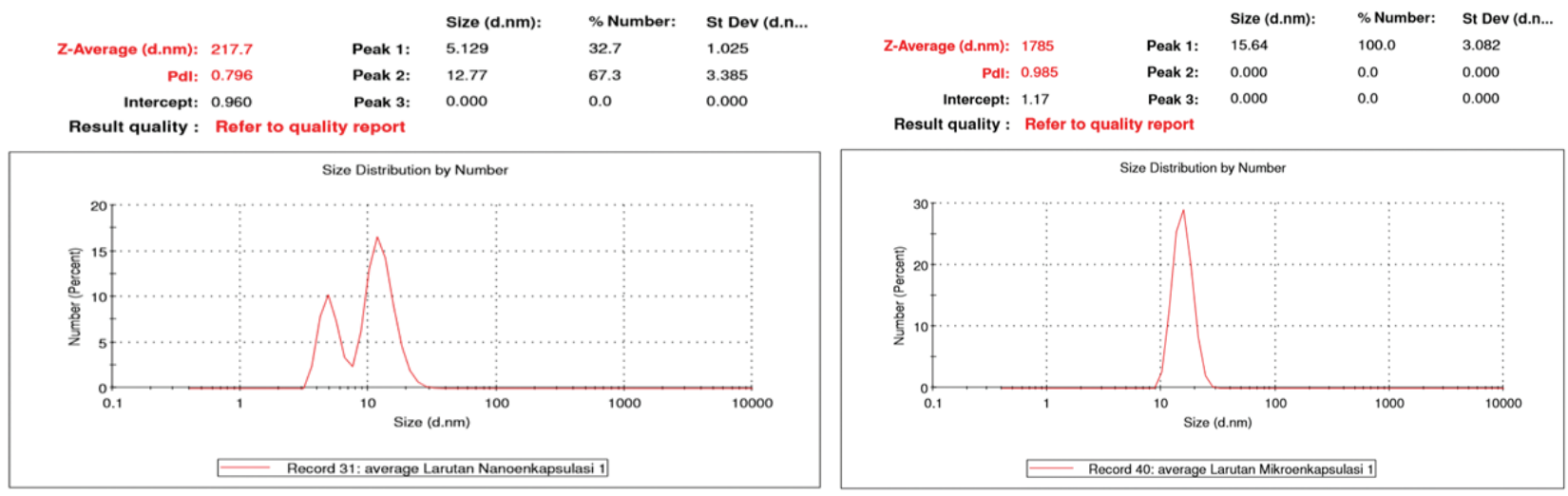

Figure 1. Particle size distribution of nano-encapsulated (a) and micro-encapsulated (b) drink powder. Particle size distribution of nano-encapsulated

Table 1. Malondialdehyde level of rats during 44 days treatment $(\mu \mathrm{M} / \mathrm{ml})$.

\begin{tabular}{lcccc}
\hline \multirow{2}{*}{ Group } & \multicolumn{4}{c}{ Day } \\
\cline { 2 - 5 } & $\mathbf{2}$ & $\mathbf{1 6}$ & $\mathbf{3 0}$ & $\mathbf{4 4}$ \\
\hline (A) Control negative & $2.802 \pm 2.062 \mathrm{a}$ & $3.969 \pm 3.427 \mathrm{a}$ & $2.546 \pm 0.846 \mathrm{a}$ & $2.018 \pm 1.256 \mathrm{a}$ \\
(B) Control positive & $4.621 \pm 3.696 \mathrm{~b}$ & $11.241 \pm 3.939 \mathrm{a}$ & $8.191 \pm 5.319 \mathrm{a}$ & $7.581 \pm 5.186 \mathrm{a}$ \\
(C) Positive diabetes-micro-encapsulation & $4.126 \pm 4.831 \mathrm{~b}$ & $11.227 \pm 5.307 \mathrm{a}$ & $8.213 \pm 3.061 \mathrm{ab}$ & $4.804 \pm 2.271 \mathrm{~b}$ \\
(D) Positive diabetes-nanoencapsulation & $4.285 \pm 3.522 \mathrm{~b}$ & $12.249 \pm 3.853 \mathrm{a}$ & $5.197 \pm 1.802 \mathrm{~b}$ & $3.643 \pm 1.954 \mathrm{~b}$ \\
\hline
\end{tabular}

Note: Different letters in the same column indicate significant differences $(p<0.05)$ after analysis of variance and a Duncan comparison test. 


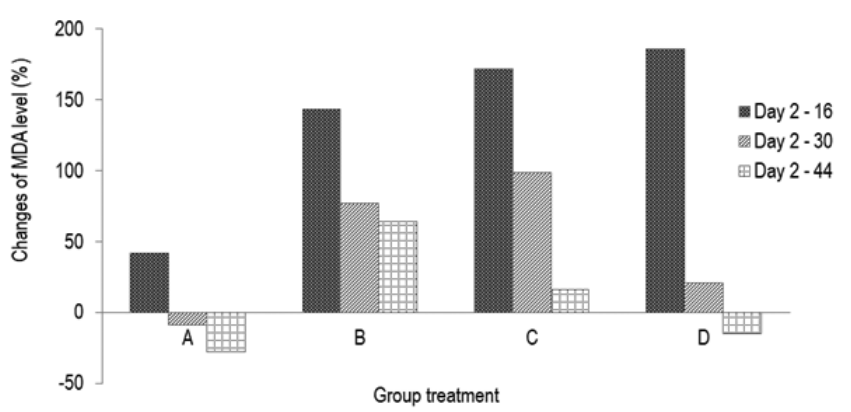

Figure 2. Changes of MDA level (\%) during 44 days compared to day 2. (A) Group negative diabetic control; (B) positive diabetic control; (C) positive diabetes-micro-encapsulation; (D) positive diabetes-nano-encapsulation.

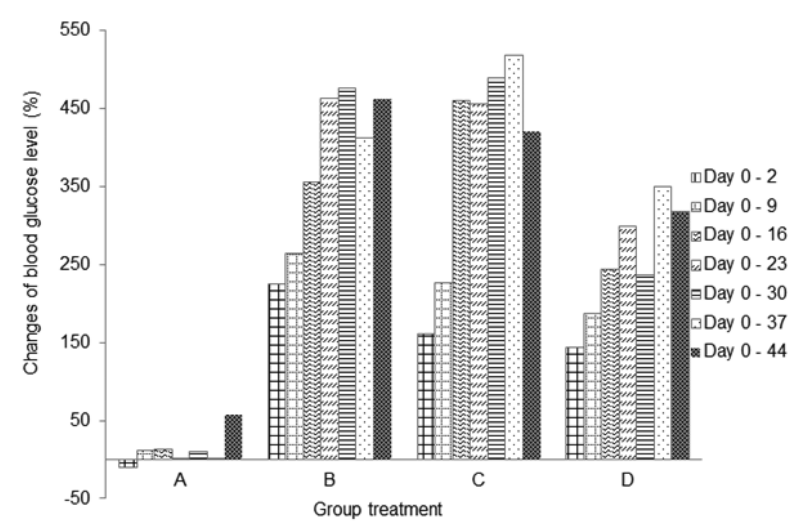

Figure 3. Changes of blood glucose level (\%) during 44 days compared to day 0. (A) Group negative diabetic control; (B) positive diabetic control; (C) positive diabetes-micro-encapsulation; (D) positive diabetes-nanoencapsulation.

rats (D), which remarkably increased to the highest level within 16 days and then significantly decreased up to normal level (nondiabetic) on day 30. At this point, the concentration of MDA was not significantly different from that of MDA level on day 44. This suggests that administration of nano-encapsulated drink for diabetic rats could reach normal level of MDA level after 30 days of treatments.

This research clearly demonstrated that encapsulation of Java tea drink was able to normalize MDA level on blood serum of diabetic rats. A study asserted the negative correlation between antioxidant activity and MDA formation (Nikniaz et al., 2015), which indicates that treatment of micro- and nano-encapsulation plays role in distributing antioxidant compounds. Microencapsulated drink suppressed MDA formation about $36.63 \%$, while nano-encapsulated drink showed a better outcome about $51.95 \%$. This suppression was associated with beneficial effects of the encapsulation on pancreatic $\beta$-cell as reported by Rekasih (2016). The decrease in MDA level was associated with inhibitory effects on lipid peroxidation since it could damage cells and DNA. In short, the lower formation of MDA contributed to less cellular damages.

There is a relation between total antioxidant status (TAS) and diabetic occurrence in human study. Diabetic patients had a lower TAS than non-diabetic patients (Kulaksizoglu and Aylin, 2016). In addition, MDA level of uncontrolled diabetic patients was higher than that in diabetic controlled patients. The uncontrolled and controlled diabetic patients had MDA level of $>10$ and $\pm 7.5 \mu \mathrm{M} / \mathrm{ml}$, respectively, while the undiabetic patients had MDA level of $\pm 5.0 \mu \mathrm{M} / \mathrm{ml}$ (Fatani et al., 2016).

\section{Blood glucose level}

The blood glucose level was checked before injection of streptozotocin. As appeared in Figure 3, it reached a diabetic condition after 48 hours. There was a fluctuation of blood glucose level on negative control group during the experiment. However, it was a normal level for blood glucose in non-diabetic rats. According to Annadurai et al. (2014), blood glucose level for diabetic rats is $>150 \mathrm{mg} / \mathrm{dl}$.

Blood glucose level in diabetic control group (B) continuously increased from days 2 to 16 (Table 2), which was significantly different $(p<0.05)$ from that on days 2 and 9. On day 16 , the blood glucose level increased and demonstrated a slight increase on day 44 . There was a fluctuation of blood glucose level in micro-encapsulation-treated rats $(C)$ after day 2. No significant difference in blood glucose level was observed within 9 days, but it dramatically increased on day 16 . The blood glucose level was fluctuating and statistically stable until day 44 . The fluctuation is caused by the malfunction of pancreatic $\beta$-cells (Murata et al., 2017) and linked with atherogenesis complications in diabetes type-2 (Xiao-Min et al., 2010). In addition, the increase of blood glucose level after induction of streptozotocin was caused by depletion of insulin secretion (Uma et al., 2014). Microencapsulation treatment statistically did not show a significant effect on blood glucose level, compared to diabetic control group. However, the blood glucose level on day 44 was lower than that on diabetic control group.

There was an increase in blood glucose level (Fig. 3) in nano-encapsulation-treated diabetic rats (D), but it was not as high as in micro-encapsulation group (C) and diabetic control group (B). There was no significant difference in blood glucose level from days 2 to 30 , which means that it is unaltered within the first 4 weeks and stable until day 44 . Our results showed that both nano- and micro-encapsulation of Java tea-based drink could suppress the incremental of blood glucose level at $45.21 \%$ and $9.89 \%$, respectively. This is quite different from previous report of 18.16\% (Rekasih, 2016).

The suppressing effect of nano-encapsulated Java teabased beverages might be related to MDA level. Another study reported that nano-encapsulation affected the distribution of the bioactive compounds and or medicine in in vivo assay using diabetic rats. Metformin and thymoquinone in nano-encapsulated form had better antihyperglycemic properties in type-2 diabetic rats. It decreased the blood glucose level better than the bioactive compounds itself (Rani et al., 2018). Encapsulation of curcumin enhanced its ability to inhibit alpha-amylase activity and antihyperglycemic activity during 7-days experiment (Akolade et al., 2017). In addition, curcumin in nanospheres conjugated to gold showed a better activity in quenching reactive oxygen species (ROS) and reactive nitrogen species (RNS) (Singh et al., 2017). 


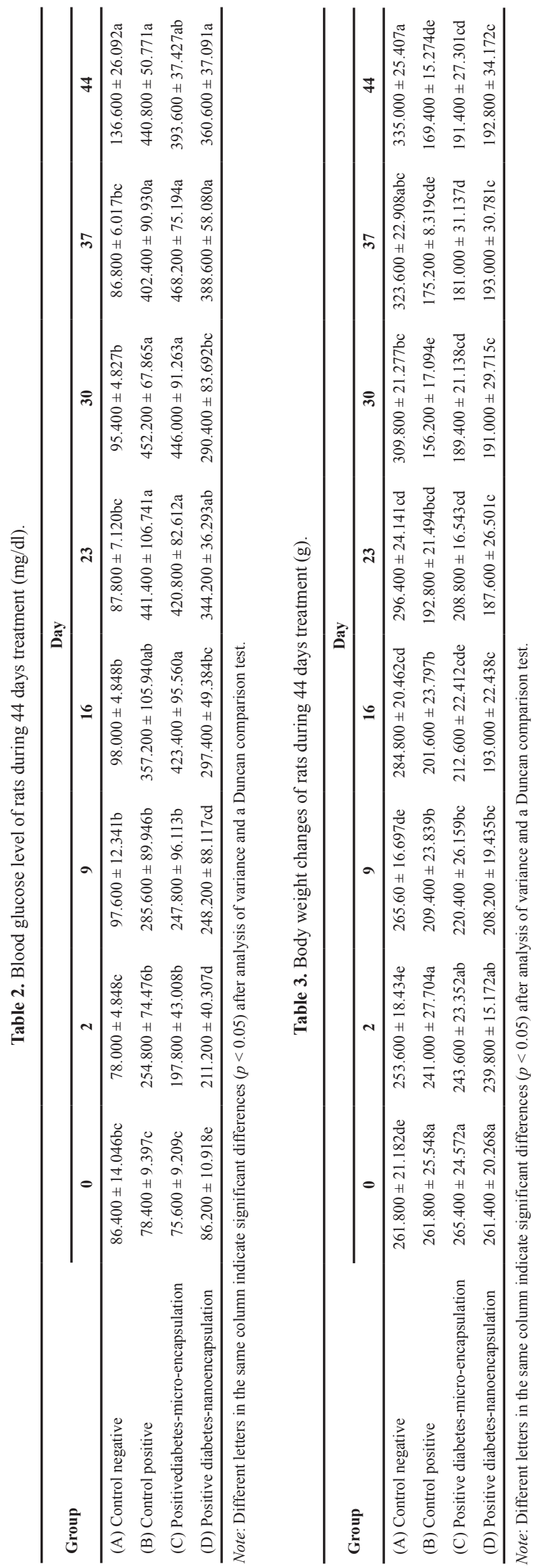

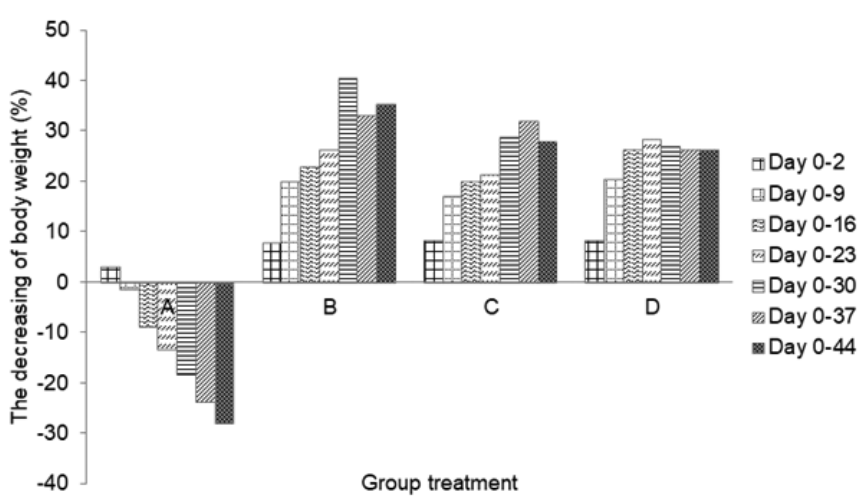

Figure 4. Changes of body weight (\%) during 44 days compared to day 0 . (A) Group negative diabetic control; (B) positive diabetic control; (C) positive diabetes-micro-encapsulation; (D) positive diabetes-nanoencapsulation. Minus $(-)$ percentage describes the increasing of body weight of rats.

\section{Body weight profile}

The rat body weight was found from 250 to $300 \mathrm{~g}$ before the induction of streptozotocin and monitored during the six weeks of the experiment (Table 3). Body weight of negative control rats (A) showed a significant increase until day 44. Furthermore, there is a decrease in body weight of diabetic rats $(\mathrm{B}, \mathrm{C}$, and $\mathrm{D})$ during experiment. The weight loss was caused by streptozotocin capable of damaging cells and DNA, reducing the weight of several organs such as liver, brain, and gonad (Cintra et al., 2017). Its concentration was negatively associated with rat weight loss (Omolaoye et al., 2018).

Administration of micro-encapsulated Java tea-based drink (C) showed a remarkable effect on the rat weight loss. The body weight significantly decreased during the first 9 days followed by a constant weight till day 30 . The decrease reached the lowest level on day 37 and started to increase to on day 44. Nano-encapsulation treatment (D) showed a positive effect on controlling the weight loss of diabetic rats (Fig. 4). Body weight decreased significantly on day 9 , and it was stable until day 44 . The results suggested that treatment of nano- and micro-encapsulation on diabetic rats was beneficial in reducing their weight loss.

The relationship between nano- and micro-encapsulation treatment and rat body weight may display a inhibitory activity against lipid peroxidation. Lipid peroxidation damaged the cells and DNA and reduced the ability of insulin action for glucose intake (Suarsana et al., 2010). As a result, the energy is insufficient for growth of rats. Rekasih (2016) reported that micro-encapsulation and nano-encapsulation of Java tea-based beverages had effects in repairing of pancreatic $\beta$-cell. In summary, the treatment could increase the body weight while also exhibiting the repairing effects.

\section{In vitro malondialdehyde level}

The results demonstrated that inhibitory effects of nanoencapsulation on MDA formation were significantly different from micro-encapsulation and positive control (vitamin E 200 ppm) as presented in Table 4. In addition, we found that MDA level for negative control $(0 \mathrm{ppm})$ was not significantly different from micro-encapsulation treatment. However, these values statistically 
Table 4. Malondialdehyde levels produced from linoleic acid with micro-encapsulation and nanoencapsulation treatment.

\begin{tabular}{ccc}
\hline \multirow{2}{*}{$\begin{array}{c}\text { Concentration } \\
(\mathbf{p p m})\end{array}$} & \multicolumn{2}{c}{ MDA level $(\boldsymbol{\mu M} / \mathbf{m l})$} \\
\cline { 2 - 3 } 0 (Negative contl) & $184.352 \pm 0.332 \mathrm{a}$ & Nanoencapsulation \\
25 & $182.775 \pm 3.005 \mathrm{ab}$ & $158.352 \pm 0.332 \mathrm{a}$ \\
50 & $183.890 \pm 4.933 \mathrm{a}$ & $133.074 \pm 5.374 \mathrm{~d}$ \\
75 & $177.234 \pm 1.751 \mathrm{ab}$ & $94.260 \pm 0.321 \mathrm{e}$ \\
100 & $173.408 \pm 4.494 \mathrm{~b}$ & $53.826 \pm 0.796 \mathrm{f}$ \\
200 & $174.682 \pm 5.641 \mathrm{ab}$ & $51.323 \pm 0.653 \mathrm{f}$ \\
\multicolumn{2}{c}{ Vitamin E } \\
\hline 200 (Positive control) & \multicolumn{2}{c}{$19.273 \pm 3.482 \mathrm{~g}$} \\
\hline
\end{tabular}

Note: Different letters in both in the column and row indicate significant differences $(p<0.05)$ after analysis of variance and a Duncan comparison test.

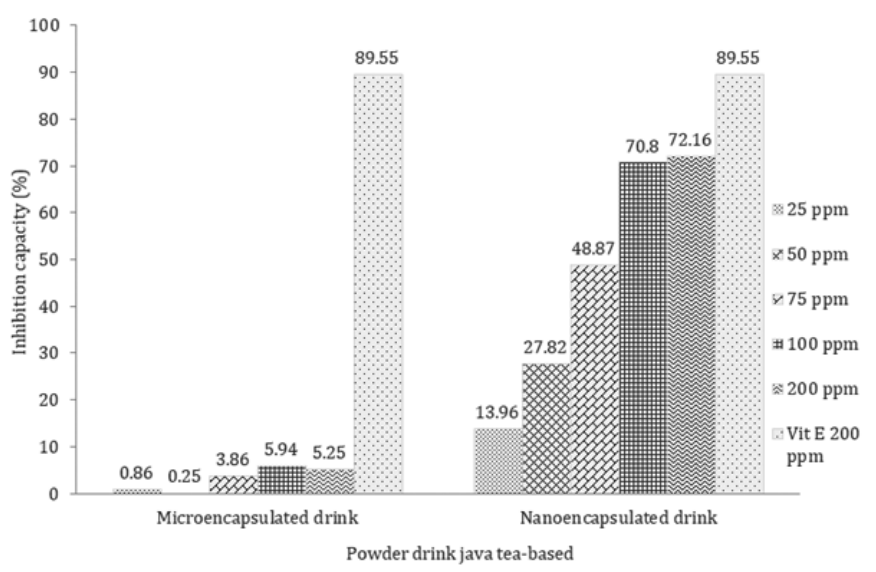

Figure 5. Inhibition activity of drink powder against the malondialdehyde formation.

showed a difference in comparison with MDA level for positive control (vitamin E).

Furthermore, MDA level derived from linoleic acid in the nano-encapsulated drink powder was significantly different from negative control, micro-encapsulated drink powder, and positive control. Our results also found that nano-encapsulation treatment significantly resulted in lower MDA level as more drink powder was provided. In terms of nano-encapsulation treatment, the highest level of MDA was attributed to $25 \mathrm{ppm}$, while the lowest was found at $200 \mathrm{ppm}$. As depicted in Figure 5, the result clearly displayed that vitamin $\mathrm{E}$ at $200 \mathrm{ppm}$ produced the highest inhibition activity on MDA level followed by nano-encapsulation and micro-encapsulation. In terms of MDA-inhibition activity, the in vitro assay showed the same result as in vivo, where nano-encapsulated drink showed the higher activity than microencapsulated drink. On diabetic rats, micro-encapsulated and nanoencapsulated drink suppressed MDA formation about $36.63 \%$ and $51.95 \%$, respectively. Melekh et al. (2017) reported that there was relation between MDA level and enzymatic antioxidant capacity such as superoxide dismutase and catalase.

\section{CONCLUSION}

Nano- and micro-encapsulation of Java tea-based beverages could alleviate the MDA formation both in vivo and in vitro assessment, enabling to control blood glucose level and body weight loss of diabetic rats. However, the mode of action on the MDA inhibition is still unclear, which may involve enzymatic or non-enzymatic pathways. Hence, further studies were required, focusing mainly on the inhibitory effects of encapsulation treatment on MDA formation. In addition, there is a need to investigate the anti-hyperglycemic activity of the powder drink in human study.

\section{ACKNOWLEDGMENTS}

The authors wish to thank Kemenrsitekdikti Hibah Kompetensi 2018 for help funding the research.

\section{REFFERENCES}

Afandi FA. The effect of nanoencapsulation on sensory, phsycochemical and physiologys properties of functional drink java-tea (Orthosiphon aristatus B1. Miq) based [Thesis] (ID). Bogor Agricultural University, 2014.

Akolade JO, Oloyede HOB, Onyenekwe PC. Encapsulation in chitosan-based polyelectrolyte complexes enhances antidiabetic activity of curcumin. J Func Foods, 2017; 35:584-94.

Alok S, Sanjay K, Amita V, Mayank K, Alok M, Monika S. Herbal antioxidant in clinical practice: a review. Asian Pac J Biomed, 2014; 4(1):78-84.

Annadurai T, Vasanthakumar A, Geraldine P, Thomas PA Variations in erythrocyte antioxidant levels and lipid peroxidation status and in serum lipid profile parameters in relation to blood haemoglobin A1c values in individuals with type 2 diabetes mellitus. Int Diab Federat, 2014; DIAB-6056:12.

Arpagaus C, Philipp J, Andreas C, David R. Nano capsules formation by nano spray drying. Nano-encapsulation Technologies for the Food and Nutraceuticals Industries. Chapter 10. Elsevier, 2017.

Cintra LTA, Renata OS, Annelise KCP, Doris HS, Eloi DJ, Joao EGF. Oral health, diabetes and body weight. Arch Oral Biol, 2017; 73:94-9.

Ezgi DC, Vural G. Evolution of food antioxidants as a core of food science for a century. Food Res Int, 2017; 105:76-93.

Ezhilarasi PN, Karthik P, Channawal N, Anandharamakrishnan C. Nanoencapsulation techniques for food bioactive components: a review. Food Bioprocess Technol, 2013; 6(3):628-47.

Fatani SH, Abdullatif TB, Essameldin MN, Abdalla AA. Lipid peroxidation is associated with poor control of type-2 of diabetes mellitus. Diabetes and Metab Syndr Clin Res Rev, 2016; 2(1):S64-7.

Food and Drug Administration (FDA). FDA regulation of nanotechnology. Duvall, MN, 2012. Available via http://apps.americanbar. org (Accessed 20 January 2018).

Gaschler MM, Stockwell BR. Lipid peroxidation in cell death. Biochem Biophys Res Commun, 2017; 482:419-25.

Indariani S, Wijaya $\mathrm{CH}$, Rahminiwati $\mathrm{M}$, Wien $\mathrm{WM}$. Antihyperglicemic activity of functional drinks based on Java tea (Orthosiphon aristatus) in streptozotocin induced diabetic mice. IFRJ, 2014; 21(1):349-55.

Jardim KV, Joanitti GA, Azevedo RB, Parize AL. Physicochemical characterization and cytotoxicity evalauation of curcumin loaded in chitosan/chondroitin sulphate nanoparticles. Mater Sci Eng C, 2015; 56:294-304.

Kikuzaki H, Nobuji N. Antioxidant effect of some ginger constituents. J Food Sci, 1993; 58(6):1407-10.

Krishnaiah D, Rosalam S, Rajesh N. A review of the antioxidant potential of medicinal plant species. Food Bioprod Process, 2011; 89:217-33.

Kulaksizoglu SMD, Aylin KMD. Aqueous humour and serum levels of nitric oxide, malondialdehyde and total antioxidant status in patients with type 2 diabetes with proliferative diabetic retinopathy and nondiabetic senile cataracs. Can J Diabetes, 2016; 40(2):115-9.

Madiseh MR, Afsaneh MT, Mahmoud B, Mahmoud RK. Review the research and development on the antioxidants in prevention of diabetic complications. Asian Pac J Trop Med, 2016; 9(9):825-31. 
Melekh B, Ilkuv I, Lozynskyi A, Sklyarov A. Antioxidant enzyme activity and lipid peroxidation in rat liver exposed to celecoxib and lansoprazole under epinephrine-induced stress. J Appl Pharm Sci, 2017; 7(10):094-9.

Minagawa T, Okamura Y, Shigemasa Y, Minami S, Okamoto Y. Effects of molecular weight and deacetylation degree of chitin/chitosan on wound healing. Carbohydr Polym, 2007; 67:640-4.

Morakinyo AO, Samuel TA, Adekunbi DA, Adegoke OA. Niacin improves adiponectin secretion, glucose tolerance and insulin sensitivity in diet-induced obese rats. Egypt J Basic Appl Sci, 2015; 2:261-7.

Murata M, Hitoshi A, Shigeru O, Masahiko K. Glucose fluctuation and the resultant endothelial injury are correlated with pancreatic beta-cell dysfunction in patients with coronary artery disease. Diabetes Res Clin Pract, 2017; 131:107-15.

Niki E. Biomarkers of lipid peroxidation in clinical material. J Biochim Biophys Acta, 2014; 1840(2):809-17.

NikniazZ, Reza M, Alireza O, Aliasghar E, Leila N, Amirmansour $\mathrm{V}$. Effects of Elaeagnus angustifolia L. powder supplementation on serum total antioxidant activity and malondialdehyde levels in female with knee osteoarthritis. J Herb Med, 2015; 117:1-7.

Noguchi HK, Naoko H, Maho M, Kiyotake S. A novel allelopathic substance, 13-epi-orthosiphol N, in Orthosiphon stamineus. J Plant Physiol, 2013; 170(1):1-5.

Ohkawa H, Nobuko O, Kunio Y. Assay for lipid peroxides in animal tissues by thiobrbituric acid reaction. Anal Biochem, 1979; 95: $351-8$.

Ojiako OA, Chikezie PC, Ogbuji AC. Blood glucose level and lipid profile of alloxan-induced hyperglycemic rats treated with single and combinatorial herbal formulations. J Tradit Complement Med, 2016; 6(2):184-92.

Omolaoye TS, Bongekile TS, Stefan SP. Diabetes mellitusinduction: effect of different streptozotocin doses on male reproductive parameters. Acta Histochem, 2018; 120(2):103-9.

Ozturk B, Argin S, Ozilgen M, McClements DJ. Formation and stabilization of nanoemulsion-based vitamin E delivery systems using natural surfactants: quillaja saponin and lecithin. J Food Eng, 2014; 142:57-63.

Rani R, Shakti D, Dinesh D, Neeraj D, Ki-Hyun K, Sandeep K. Improvement of antihyperglycemic activity of nano-thymoquinone in rat model of type-2 diabetes. Chem Biol Interact, 2018; 295:119-132.

Rekasih M. Antihyperglycemic activity of Java tea-based functional drink-loaded chitosan nanoparticle in streptozotocin-induced diabetic rats. Thesis, Bogor Agricultural University, Indonesia, 2016.

Safithri MH, Sedarnawati S, Maria B, Anna SR. Antihyperglycemic activity of Piper crocatum leaves and Cinnamon burmannii bark mixture extract in streptozotocin-induced diabetic rats. J Math Fund Sci, 2016; 48(2):178-91.

Singh LM, Chakraborty B, Pal R, Nath A, Pal S, Rahman DS, Ghosh SK, Sengupta M. A comparative study on the antioxidant and immunomodulatory properties of curcumin conjugated gold nanospheres and free curcumin. J Appl Pharm Sci, 2017; 7(11):056-63.
Suarsana IN, Priosoeryanto BP, Wresdiyati T, Bintang M. Synthesis glycogen of liver and muscle in diabetic rats fed tempeh extracts J Vet, 2010; 11(3):190-5.

Surya S, Abdul DS, Dawn VT, Betty C, Ravindrakurup AK, Christudas S. Diabetes mellitus and medical plants-a review. Asian Pac J Trop Dis, 2014; 4(5):337-47.

Uma C, Suganyaa N, Vanitha P, Bhakkiyalakshmi E, Suriyanarayanan S, John KMM, Sivasubramanian S, Gunasekaran P, Ramkumar KM. Antihyperglycemic effect of Codariocalyx motorius modulated carbohydrate metabolic enzyme activities in streptozotocininduced diabetic rats. J Funct Foods, 2014; 11:517-27.

Vijay P, Sharma V. The role of natural antioxidants in oxidative stress induced diabetes mellitus. Res J Pharm Sci, 2014; 3(4):1-6.

Wijaya CH, Achmadi SS, Herold, Indariani S. Formulation and making process of Java tea-based functional drink (Orthosiphon aristatus). Patent P00200700564, Bogor Agriculture University, Indonesia, 2007.

Wijaya CH, Nurtama B, Afandi FA. Effect of nanoencapsulation on the sensory, physicochemical, and functional quality of Java Tea base functional drink (Orthosiphon aristatus B1. Miq). Patent P00201304918, Bogor Agriculture University, Indonesia, 2013.

Wijaya CH, Rahminiwati M, Chen H, Kordial N, Lo D. In vitro and ex vivo anti-hyperglycemic activities of Java tea (Orthosiphon aristatus BI. Miq) — based functional drink. In Proceeding of 15th World Congress of Food Science and Technology, Cape Town, Afrika Selatan, 2010.

Wijaya CH, Sutisna N, Nurtama B, Muhandri T, Indarian S. Development of java tea based functional drink: scale-up formula optimization based on the sensory and antioxidant properties. J Appl Pharm Sci, 2018; 8(09):055-60.

Wu Y, Luo Y, Wang Q. Antioxidant and antimicrobial properties of essensial oils encapsulated in zein nanoparticles prepared by liquidliquid dispersion method. J Food Sci Tech, 2012; 48:283-90.

Xiao-Min C, Yan Z, Xing-Ping S, Qun H, Hong M, Yang-Ling H, Wen-Qiang Z, Hao-Jie W. Correlation between glucose fluctuations and carotid intima-media thickness in type-2 diabetes. Diabetes Res Clin Pract, 2010; 90(1):95-9.

Yagi K. Lipid peroxidation and human diseases. Chem Phys Lipids, 1987; 45:337-51.

How to cite this article:

Naibaho J, Safithri M, Wijaya CH. Anti-hyperglycemic activity of encapsulated Java tea-based drink on malondialdehyde formation. J Appl Pharm Sci, 2019; 9(04):088-095. 